Article

\title{
Identifying Iron-Bearing Nanoparticle Precursor for Thermal Transformation into the Highly Active Hematite Photo-Fenton Catalyst
}

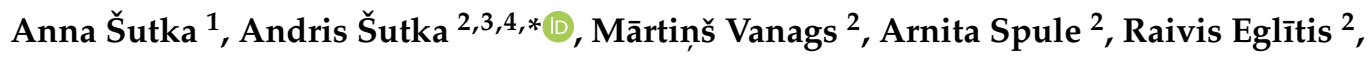 \\ Svetlana Vihodceva ${ }^{2}$, Krišjānis Šmits ${ }^{5}$, Aile Tamm ${ }^{4}$ and Linda Mežule ${ }^{6}$ \\ 1 Biomaterials Research Laboratory, Institute of Inorganic Chemistry, Faculty of Materials Science \\ and Applied Chemistry, Riga Technical University, Paula Valdena 3/7, 1048 Riga, Latvia; anna.sutka@rtu.lv \\ 2 Research Laboratory of Functional Materials Technologies, Faculty of Materials Science and \\ Applied Chemistry, Riga Technical University, Paula Valdena 3/7, 1048 Riga, Latvia; \\ Martins.Vanags_4@rtu.lv (M.V.); arnita.spule@rtu.lv (A.S.); raivis.eglitis_1@rtu.lv (R.E.); \\ Svetlana.Vihodceva@rtu.lv (S.V.) \\ 3 Institute of Atomic physics and spectroscopy, University of Latvia, Skunu 4, 1050 Riga, Latvia \\ 4 Institute of Physics, University of Tartu, W. Ostwaldi Street 1, 50411 Tartu, Estonia; aile.tamm@ut.ee \\ 5 Institute of Solid State Physics, University of Latvia, Kengaraga 8, LV-1063 Riga, Latvia; smits@cfi.lu.lv \\ 6 Water Research Laboratory, Faculty of Civil Engineering, Riga Technical University, Paula Valdena 1, \\ 1048 Riga, Latvia; linda.mezule@rtu.lv \\ * Correspondence: andris.sutka@rtu.lv; Tel.: +371-26-138-155
}

Received: 19 June 2020; Accepted: 10 July 2020; Published: 12 July 2020

\begin{abstract}
The hematite photo-Fenton catalysis has attracted increasing attention because it offers strong oxidation of organic pollutants under visible light at neutral $\mathrm{pH}$. In the present work, aqueous synthesis of hematite photo-Fenton catalysts with high activity is demonstrated. We compare photo-Fenton activity for hematite obtained by hydrolyzation at $60^{\circ} \mathrm{C}$ or by a thermally induced transformation from iron-bearing nanoparticles, such as amorphous iron oxyhydroxide or goethite. A link between their structure and visible light photo-Fenton reactivity is established. The highest activity was observed for hematite obtained from goethite nanowires due to oblong platelet-like structure, high surface area and the presence of nanopores.
\end{abstract}

Keywords: hematite; photo-Fenton; goethite; water purification

\section{Introduction}

The number of published research works devoted to the heterogeneous photo-Fenton advanced oxidation process (AOP) has been drastically increasing in the last few years. This is because abundant non-toxic iron oxide-based catalysts can be used and the water treatment process can be driven by visible light. Moreover, contrary to homogeneous Fenton reaction which occurs under acidic conditions [1], the photo-Fenton reaction can be driven at neutral $\mathrm{pH}$, thus avoiding the use of acids for triggering a reaction and bases for the neutralization afterward, as well as the formation of iron sludge by-product. In the heterogeneous photo-Fenton process, the photoexcited iron compound reacts with $\mathrm{H}_{2} \mathrm{O}_{2}$ and forms different reactive oxygen species (ROS), such as hydroxyl, hydroperoxyl and superoxide radicals following Equations (1)-(8) [2,3]. The superoxide radical is especially important to destroy persistent organic pollutants in water. The reduction potential of photoinduced electrons in hematite is not high enough to produce superoxide radical directly from oxygen, but in photo-Fenton 
reaction with $\mathrm{H}_{2} \mathrm{O}_{2}$ superoxide, radicals could be produced by Equations (7) and (8). However, in the photo-Fenton process, the dominating ROS generated from $\mathrm{H}_{2} \mathrm{O}_{2}$ is $\mathrm{OH}^{\bullet}$ [2].

$$
\begin{gathered}
\mathrm{Fe}_{2} \mathrm{O}_{3} \stackrel{\text { h }}{\rightarrow} \mathrm{Fe}_{2} \mathrm{O}_{3}\left(\mathrm{~h}^{+}+\mathrm{e}^{-}\right) \\
\mathrm{Fe}^{3+}+\mathrm{e}^{-} \rightarrow \mathrm{Fe}^{2+} \\
\mathrm{Fe}^{2+}+\mathrm{H}_{2} \mathrm{O}_{2} \rightarrow \mathrm{Fe}^{3+}+\mathrm{OH}^{\bullet}+\mathrm{OH}^{-} \\
\mathrm{H}_{2} \mathrm{O}_{2}+\mathrm{e}^{-} \rightarrow \mathrm{OH}^{\bullet}+\mathrm{OH}^{-} \\
\mathrm{H}_{2} \mathrm{O}+\mathrm{h}^{+} \rightarrow \mathrm{OH}^{\bullet}+\mathrm{H}^{+} \\
\mathrm{h}^{+}+\mathrm{OH}^{-} \rightarrow \mathrm{OH}^{\bullet} \\
\mathrm{OH}^{\bullet}+\mathrm{H}_{2} \mathrm{O}_{2} \rightarrow \mathrm{H}_{2} \mathrm{O}+\mathrm{HO}_{2}^{\bullet} \\
\mathrm{HO}_{2}^{\bullet} \rightarrow \mathrm{O}_{2}^{-\bullet}+\mathrm{H}^{+}
\end{gathered}
$$

Different materials for heterogeneous photo-Fenton catalysts have been reported, such as $\alpha-, \beta-, \gamma-\mathrm{Fe}_{2} \mathrm{O}_{3}$ [4-8], $\mathrm{Fe}_{3} \mathrm{O}_{4}$ [9], $\mathrm{FeO}[9], \alpha-, \beta-\mathrm{FeOOH}[10,11], \mathrm{LaFeO}_{3}$ [12], $\mathrm{BiFeO}_{3}$ [13], $\mathrm{Fe}_{2}\left(\mathrm{MeO}_{4}\right)_{3}$ [3] and spinel ferrites $\mathrm{MFe}_{2} \mathrm{O}_{4}$ (where $\mathrm{M}$ is divalent metal cation) [14,15]. Additionally, the catalytic activity towards photo-Fenton reaction can be enhanced by synthesizing heterostructures with metals [2], metal oxides [16] and graphitic $\mathrm{C}_{3} \mathrm{~N}_{4}$ [17]. The photoinduced charges are spatially separated over nanoheterostructures, thus decreasing the recombination rate [16]. Among all photo-Fenton catalysts, the hematite is especially attractive because a large variety of straightforward synthesis approaches can be used. Hematite is chemically stable and non-toxic. More importantly, hematite shows photo-Fenton catalytical activity in neutral conditions and under visible light $[5,18]$. Besides, the hematite has a highly positive valence band maximum potential resulting in a strong oxidation power of photogenerated holes, which could be suitable for direct organic pollution degradation [19]. Complex iron oxides, such as spinel ferrites, for example, shows photo-Fenton activity under acidic conditions [15]. Acidic conditions may trigger iron oxides or oxyhydroxides to dissolve and leach iron, thus decreasing stability and reducing activity [20].

The heterogeneous photo-Fenton catalytic activity of hematite is determined by surface exposed crystal facets [5], area and geometric shape [6]. The higher heterogeneous photo-Fenton catalytic activity is reported for $\{110\}$ facets due to the higher density of unsaturated surface iron cations bonded to five oxygen [5]. Higher activity of hematite nanocrystals with the dominant $\{110\}$ facets exposed to the surface could also be related to the higher density of Fe atoms on a plane [21].

Another approach to control the properties of desired target materials is to use different nanoparticle precursors [22]. Hematite can be obtained by thermal phase transformation from a large variety of iron-bearing nanoparticles, i.e., oxides and oxyhydroxides, because it is the thermal transformation final product for most of them [23]. However, the photo-Fenton activity for hematite nanoparticles obtained by a thermal transformation from various iron-bearing nanoparticle precursors has not yet been studied so far. At the same time, there are broad research possibilities because several nanoparticle shapes have been synthesized for iron oxides and oxyhydroxides, for example, nanoplates [24], nanowires [25], nanostructured urchin-like hollow spheres [26] and nanotubes [27]. This allows one to potentially obtain a large variety of different hematite nanostructures, with a potential to produce highly active photo-Fenton catalysts. In the present study, we are investigating photo-Fenton activity for hematite obtained directly by hydrolyzation at room temperature or by thermally induced structural transformation of iron oxyhydroxide amorphous nanoparticles or goethite nanowires. During the heating of all oxyhydroxides, dehydroxylation occurs alongside with thermal transformation to hematite. Due to the expulsion of water, nanopores are formed, thus increasing the specific surface area [23]. This resulted in the formation of a highly active hematite photo-Fenton nanocatalyst. 


\section{Results and Discussions}

\subsection{The Crystalline Structure and Morphology of Iron-Bearing Nanoparticle Precursors and Photo-Fenton Catalysts}

The photo-Fenton hematite nanoparticle catalysts were obtained by a thermal transformation from various iron-bearing nanoparticle precursors or by direct hydrolyzation of iron (iii) nitrate at room temperature.

Amorphous $\mathrm{FeO}(\mathrm{OH})$ precursor was obtained by using HMTA as a precipitating agent as described before [28]. No peaks related to crystalline phases were observed in amorphous iron-containing precipitates, as shown by XRD studies (Figure 1). As it is demonstrated in SEM images in Figure 2a, the amorphous iron-containing precipitated particles have a non-uniform spherical shape, with sizes from $38 \mathrm{~nm}$ to $85 \mathrm{~nm}$. The amorphous nanoparticles are packed in dense agglomerates. After annealing, the amorphous precipitates are transformed into the hematite phase (ICDD 04-006-0285) as indicated by XRD (Figure 1) and particles have grown to larger sizes from $89 \mathrm{~nm}$ to $264 \mathrm{~nm}$ as seen from SEM image (Figure 2b).

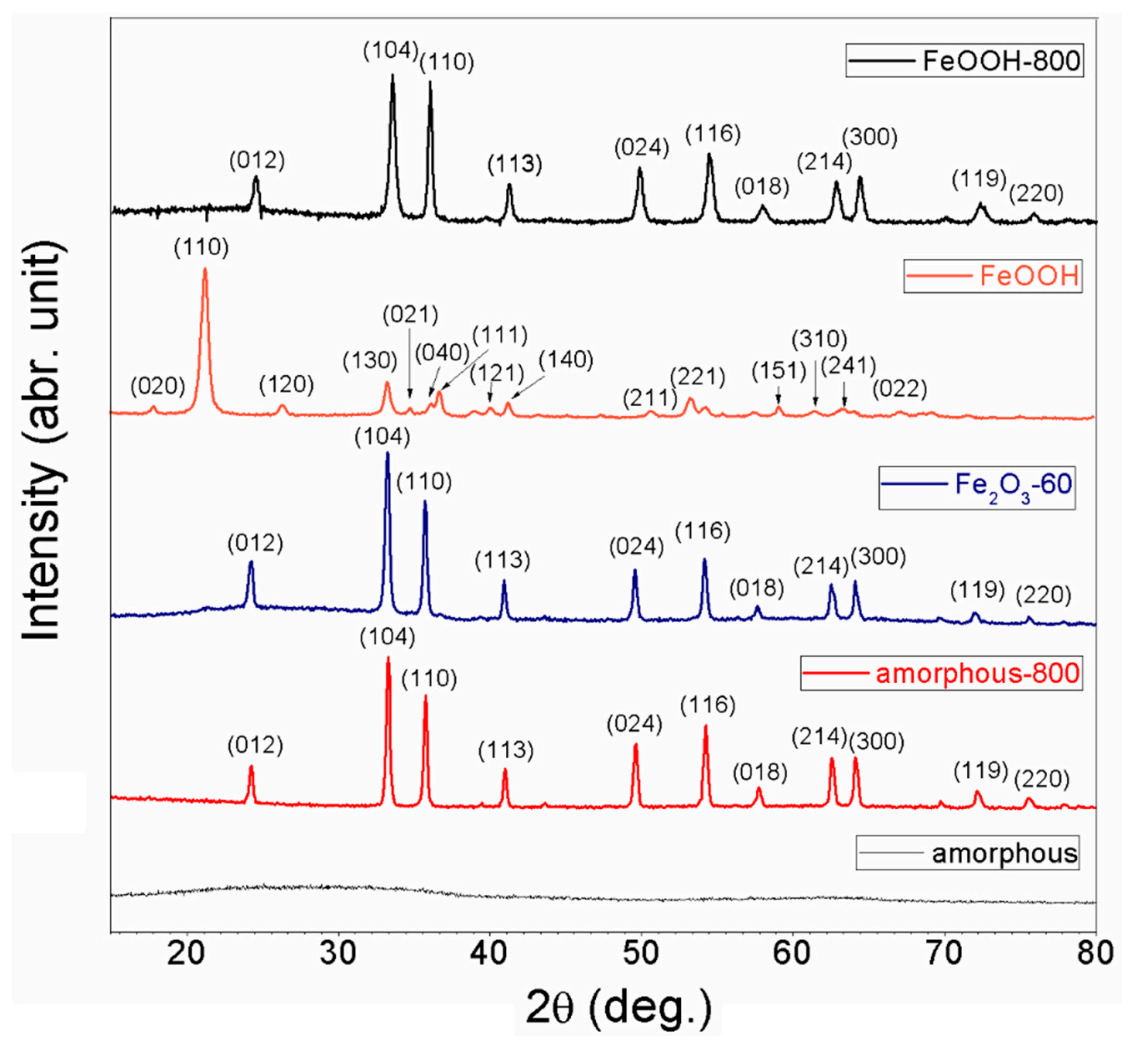

Figure 1. The XRD patterns of synthesized samples: amorphous-amorphous iron-containing precipitates; amorphous-800-hematite obtained from amorphous iron-containing precipitates after annealing at $800{ }^{\circ} \mathrm{C} ; \mathrm{Fe}_{2} \mathrm{O}_{3}-60$ - synthesized by hydrolysis directly from solution at $60^{\circ} \mathrm{C} ; \mathrm{FeOOH}$ - goethite $\alpha$-FeOOH synthesized directly from solution at $60^{\circ} \mathrm{C}$; FeOOH-800-hematite obtained from goethite after annealing at $800{ }^{\circ} \mathrm{C}$.

Single-phase goethite precursor was synthesized by precipitation using $\mathrm{NaOH}$ at $\mathrm{pH}>12$ as clearly indicated by powder XRD studies (Figure 1). Diffractograms exhibit strong peaks related to the goethite phase (ICDD 04-015-2899). No impurity phases were observed. As expected, precipitated goethite particles have a one-dimensional nanowire shape with length from $270 \mathrm{~nm}$ to $470 \mathrm{~nm}$ and diameter from $10 \mathrm{~nm}$ to $30 \mathrm{~nm}$ as seen from SEM image Figure 2c. TEM image for goethite precipitates (ESI Figure S1) shows that the majority of nanowires are grouped in bundles. The diameter of a single nanowire is around $20 \pm 5 \mathrm{~nm}$. Annealing transforms goethite to hematite (ICDD 04-006-0285), 
as indicated by XRD (Figure 1), while simultaneously keeping the one-dimensional shape, as seen from SEM image (Figure 2d). After closer examination by TEM (Figure 2f), the hematite particles obtained from goethite contain pores. This is due to the expulsion of water during the transformation by Equation (9) [23]. The nanosized pores were not observed by TEM for bare $\alpha$-FeOOH (ESI Figure S1). The nanosized pores increase the specific surface area, thus providing more active sites for the catalytic reaction. More interestingly, the $\alpha-\mathrm{FeOOH}$ nanowires, during the transformation to hematite, are adapting a two-dimensional nanoplatelet shape as noticeable from SEM image (Figure 2d) and clearly visible in TEM images taken from different angles (Figure 2f).

$$
2 \mathrm{FeOOH} \stackrel{\mathrm{t}}{\rightarrow} \mathrm{Fe}_{2} \mathrm{O}_{3}+\mathrm{H}_{2} \mathrm{O}
$$
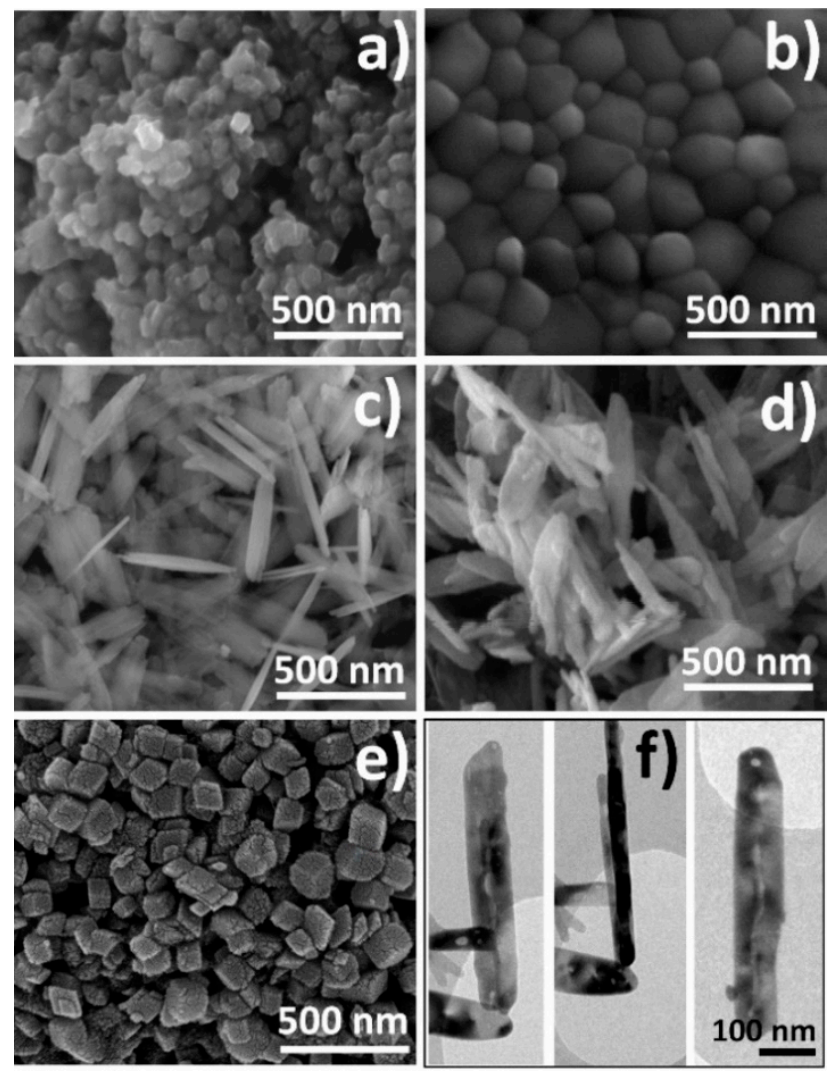

Figure 2. SEM images: (a) amorphous iron-containing precipitates, (b) hematite obtained from amorphous iron-containing precipitates after annealing at $800{ }^{\circ} \mathrm{C},(\mathrm{c})$ goethite $\alpha$-FeOOH synthesized directly from solution at $60^{\circ} \mathrm{C},(\mathbf{d})$ hematite obtained from goethite after annealing at $800^{\circ} \mathrm{C},(\mathbf{e})$ hematite synthesized by hydrolysis directly from solution at $60^{\circ} \mathrm{C}$. TEM images (f): hematite obtained from goethite after annealing at $800{ }^{\circ} \mathrm{C}$-the images on left and the middle has been taken at different angles to prove the nanoplatelet morphology and image on the right clearly shows formation of nanopores into the structure.

Finally, the hematite $\alpha-\mathrm{Fe}_{2} \mathrm{O}_{3}$ photo-Fenton catalysts were obtained directly from solution at $60{ }^{\circ} \mathrm{C}$. The hematite formation in water under acidic conditions $\mathrm{pH}<2.8$ is well reported [29]. The iron polynuclear is first formed in the aqueous solution by adding $\mathrm{NaOH}$ but keeping conditions acidic. This polynuclear is further rearranged and transformed into hematite [30]. The XRD studies confirm monophasic $\alpha-\mathrm{Fe}_{2} \mathrm{O}_{3}$ (ICDD 04-008-7623) formation directly from solution at $60{ }^{\circ} \mathrm{C}$ after $72 \mathrm{~h}$. The SEM images (Figure 2e) show that the sizes of the obtained individual hematite particles are well below $10 \mathrm{~nm}$ and, upon drying, are self-assembled in secondary cube-like particles, with sizes from 100 to $266 \mathrm{~nm}$. 
The important parameter which influences the catalytic activity of the materials is the specific surface area $(\sigma B E T)$, which was studied for all samples under study. The amorphous iron-containing nanoparticles exhibit the highest $\sigma B E T-115.7 \mathrm{~m}^{2} / \mathrm{g}$. After annealing, the $\sigma B E T$ for amorphous particles decreases to $2.6 \mathrm{~m}^{2} / \mathrm{g}$. For goethite $\alpha-\mathrm{FeOOH}$, the measured $\sigma B E T$ was $92.7 \mathrm{~m}^{2} / \mathrm{g}$ and decreases to $28.8 \mathrm{~m}^{2} / \mathrm{g}$. The specific surface area for hematite obtained directly by hydrolyzation at room temperature was $106.3 \mathrm{~m}^{2} / \mathrm{g}$.

The UV-vis-NIR absorption spectra (Kubelka-Munk function) of the synthesized samples are demonstrated in ESI Figure S2a. All hematite samples showed a sharp adsorption edge below $590 \mathrm{~nm}$ indicating a narrow optical bandgap. A similar trend was observed for goethite, with adsorption edge at around $520 \mathrm{~nm}$. The optical bandgap values (indirect transition) for hematite were obtained from the optical absorption versus photon energy plots $(\alpha \mathrm{h} v)^{1 / 2}$ by extrapolating linear fits of the plots to zero, as demonstrated in ESI Figure S2b [31]. The observed bandgap values for hematite samples, amorphous-800 (1.89 eV), $\mathrm{Fe}_{2} \mathrm{O}_{3}-60(1.97 \mathrm{eV})$ and $\mathrm{FeOOH}-800(1.98 \mathrm{eV})$ corresponds well with literature data. The band gap values for hematite depends on the synthesis approach and are between 1.9 to $2.2 \mathrm{eV}$ [32]. The bandgap value $2.33 \mathrm{eV}$ for goethite (direct transition) was observed from optical absorption versus photon energy plots $(\alpha \mathrm{h} v)^{2}$, as demonstrated in ESI Figure S2c. The observed bandgap value for goethite is in good agreement with previously reported values [25].

\subsection{Photocatalytic and Photo-Fenton Activity}

The visible-light photocatalytic performance of synthesized materials is demonstrated in Figure 3a by methylene blue (MB) degradation, which was evaluated from the change of the most intense absorption peak of MB at $665 \mathrm{~nm}$. All catalyst materials under the study were photocatalytically inactive because the $\mathrm{MB}$ in light and in the absence of any catalyst material shows faster degradation due to photolysis. The $\mathrm{C} / \mathrm{C}_{0}$ value in $120 \mathrm{~min}$ for $\mathrm{MB}$ decreased by approximately $30 \%$, while the addition of catalyst reduced the degradation to about $20 \%$. This is attributed to the light scattering by dispersed particles which hinder the penetration of photons into the MB solution [33].

The situation was noticeably changed by $\mathrm{H}_{2} \mathrm{O}_{2}$ addition in the photo-Fenton process (Figure $3 b$ ). All materials degraded MB completely in less than $120 \mathrm{~min}$. However, hematite obtained from goethite (sample FeOOH-800) destroyed over 95\% of MB in only $15 \mathrm{~min}$. The corresponding UV-vis spectral curves of $\mathrm{MB}$ solution in the photo-Fenton degradation process in the presence of hematite (FeOOH-800) sample was demonstrated in ESI Figure S3. The hematite obtained from goethite showed higher performance than polyhedrons with exposed $\{101\}$ facets, which degraded MB at the same concentration in $60 \mathrm{~min}$ [4]. $\mathrm{MB}$ alone in presence of $\mathrm{H}_{2} \mathrm{O}_{2}$ under visible light degraded only by $70 \%$ in $120 \mathrm{~min}$. The rate constants for $\mathrm{MB}$ degradation in $15 \mathrm{~min}$ for different materials decreased as follows: $\left.\mathrm{FeOOH}-800\left(0.2 \mathrm{~min}^{-1}\right)>\mathrm{Fe}_{2} \mathrm{O}_{3} \mathrm{RT} 0.07 \mathrm{~min}^{-1}\right)>$ amorphous $\left(0.05 \mathrm{~min}^{-1}\right)>$ amorphous-800 $\left(0.05 \mathrm{~min}^{-1}\right)>$ goethite $\left(0.04 \mathrm{~min}^{-1}\right)$. The higher photo-Fenton activity for hematite obtained by annealing goethite (FeOOH-800) can be attributed to its high surface area, although it should not be the single reason, because $\mathrm{Fe}_{2} \mathrm{O}_{3}$ sample obtained by hydrolysation at $60{ }^{\circ} \mathrm{C}$ shows 4 times higher $\sigma B E T$. The other reason for the high $\mathrm{FeOOH}-800$ activity could be its oblong nanoplatelet structure. It has been reported before that the recombination of photogenerated charge carriers is suppressed in one-dimensional materials [34]. Another reason for enhanced photo-Fenton activity could be the presence of nanopores in the FeOOH- 800 sample, as suggested by TEM studies. The theoretical studies show that the catalytic activity can be enhanced in materials with pore sizes at the nanoscale [18].

The observed photo-Fenton activity of hematite (FeOOH-800) is a solely heterogeneous process and cannot be related to dissolution and leaching of iron from catalytic material. To prove this, we irradiated the FeOOH-800 sample in water in the presence of $\mathrm{H}_{2} \mathrm{O}_{2}$ for $24 \mathrm{~h}$. After irradiation, the catalytic material was removed and $\mathrm{MB}(10 \mathrm{mg} / \mathrm{L})$ and $\mathrm{H}_{2} \mathrm{O}_{2}(161 \mu \mathrm{mol} / \mathrm{mL})$ were added to the water to test the homogeneous Fenton process in the dark at $\mathrm{pH}=3$. The degradation rate of $\mathrm{MB}$ was the same as in freshwater in the presence of $\mathrm{H}_{2} \mathrm{O}_{2}$ (ESI Figure S4). It has been also reported that the solubility of hematite at neutral conditions was extremely low $\left(\mathrm{k} \sim 3 \times 10^{-42}\right.$ in low ionic solution at $\left.25^{\circ} \mathrm{C}\right)$ [35]. 

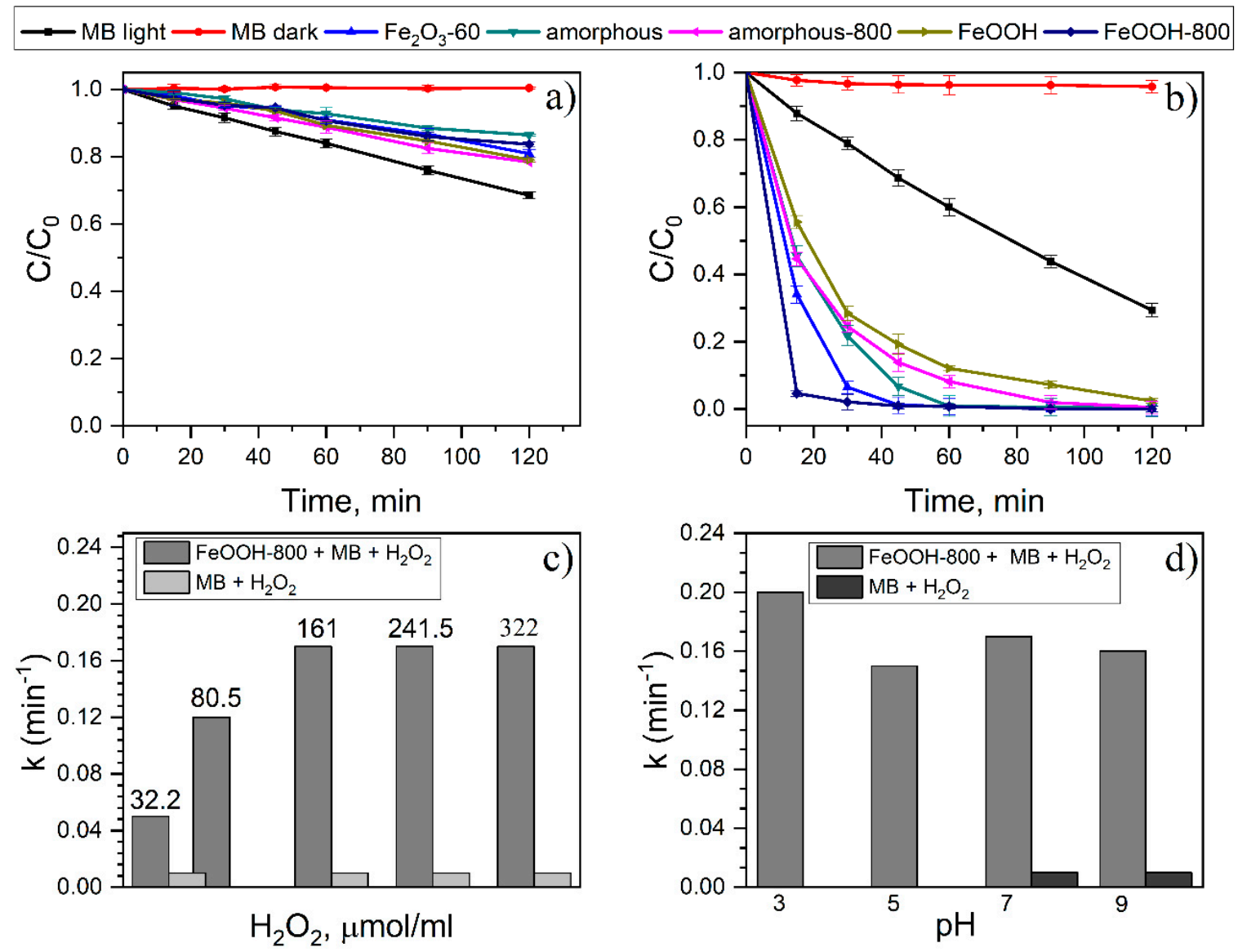

Figure 3. The photocatalytic (a) and photo-Fenton (b) catalytic degradation of $\mathrm{MB}$ in the presence of different synthesized materials under visible light at neutral $\mathrm{pH}$. The influence of $\mathrm{H}_{2} \mathrm{O}_{2}$ concentration (c) and $\mathrm{pH}$ (d) on $\mathrm{MB}$ degradation rate constant $\mathrm{k}$ in photo-Fenton process by hematite obtained by thermal transformation of goethite $\alpha-\mathrm{FeOOH}$ (sample name $\mathrm{FeOOH}-800$ ).

The photo-Fenton activity for the FeOOH-800 sample was investigated in dependence from $\mathrm{H}_{2} \mathrm{O}_{2}$ concentration (Figure $3 \mathrm{c}$ and ESI Figure S5). The activity increases by increasing the $\mathrm{H}_{2} \mathrm{O}_{2}$ concentration from $32.2 \mu \mathrm{mol} / \mathrm{mL}$ and saturates after reaching the concentration of $161 \mu \mathrm{mol} / \mathrm{mL}$. The excess $\mathrm{H}_{2} \mathrm{O}_{2}$ is not good for the photo-Fenton process, because of generated $\mathrm{OH}^{\bullet}$ radicals reacting with the excess peroxide and form $\mathrm{H}_{2} \mathrm{O}$ and $\mathrm{O}_{2}$ in following Equation (10) [16]:

$$
2 \mathrm{OH}^{\bullet}+\mathrm{H}_{2} \mathrm{O}_{2} \rightarrow 2 \mathrm{H}_{2} \mathrm{O}+\mathrm{O}_{2}
$$

The hematite photo-Fenton (FeOOH-800) catalyst shown invariable activity dependence from $\mathrm{pH}$ (Figure 3d and ESI Figure S6), which is expected behavior for hematite $[5,18]$. The rate constant for $\mathrm{MB}$ degradation, at $\mathrm{pH}=3$, was only $10 \%$ higher than at $\mathrm{pH}=7$. This is a clear advantage over other catalytic materials or homogeneous Fenton proceses (which require acidic conditions) and an important point for practical water treatment applications where using additional acidification may be costly and harm the catalytic material.

$\mathrm{MB}$ is easy to degrade; thus, we tested the photo-Fenton activity also for other more persistent dyes such as methylene orange (MO) and rhodamine-B (RhB). As can be seen in Figure 4, the degradation rate is slower, but still considerably fast if we consider that a relatively low intensity LED light source has been used in the experiments. Over $95 \%$ of MO is destroyed in $60 \mathrm{~min}$, while $70 \%$ of RhB is destroyed in $120 \mathrm{~min}$. The experiments show that the synthesized photo-Fenton catalysts could be used for a large variety of organic dye degradation in water treatment applications. The dyes were 
degraded by $\mathrm{OH} \bullet$ radicals generated in the photo-Fenton process, which is the dominant ROS in the photo-Fenton process [2].
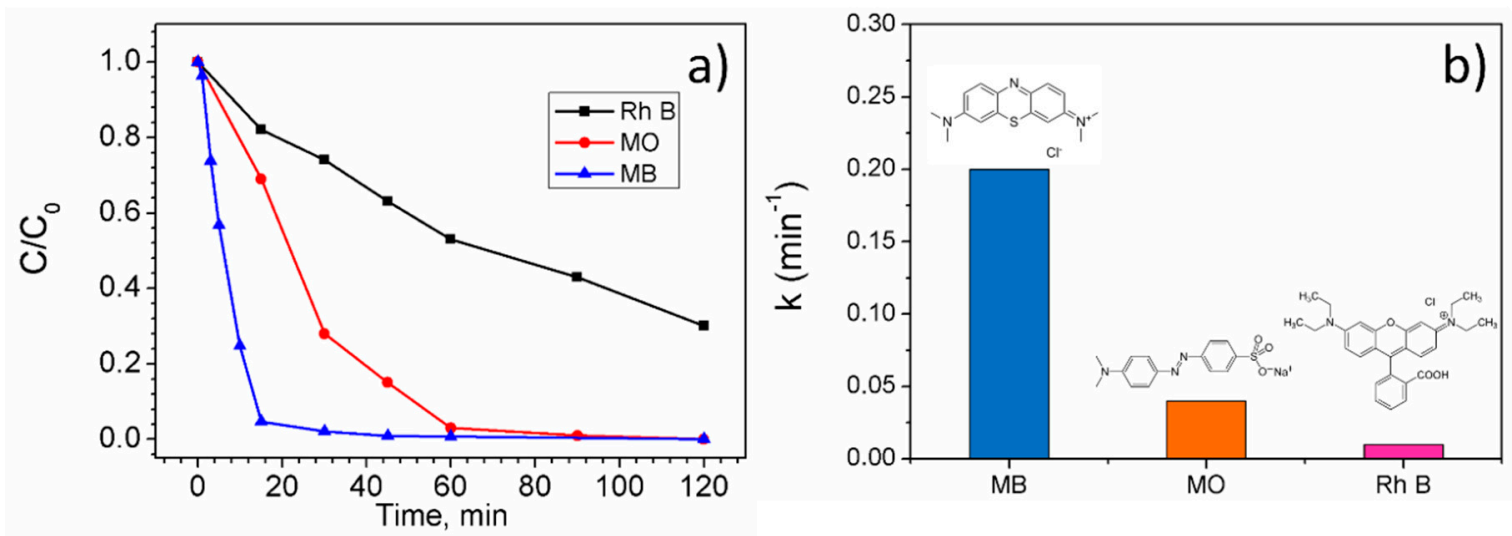

Figure 4. The relative concentration of dyes at different reaction times (a) and corresponding rate constants (b).

The synthesized hematite photo-Fenton (FeOOH-800) catalyst was completely stable under the photo-Fenton process at neutral conditions. The recycling test was carried out by degrading the MB and no decrease in the activity of hematite photo-Fenton catalyst was observed after seven cycles, as demonstrated in Figure 5, showing that the material can be safely used over and over again.

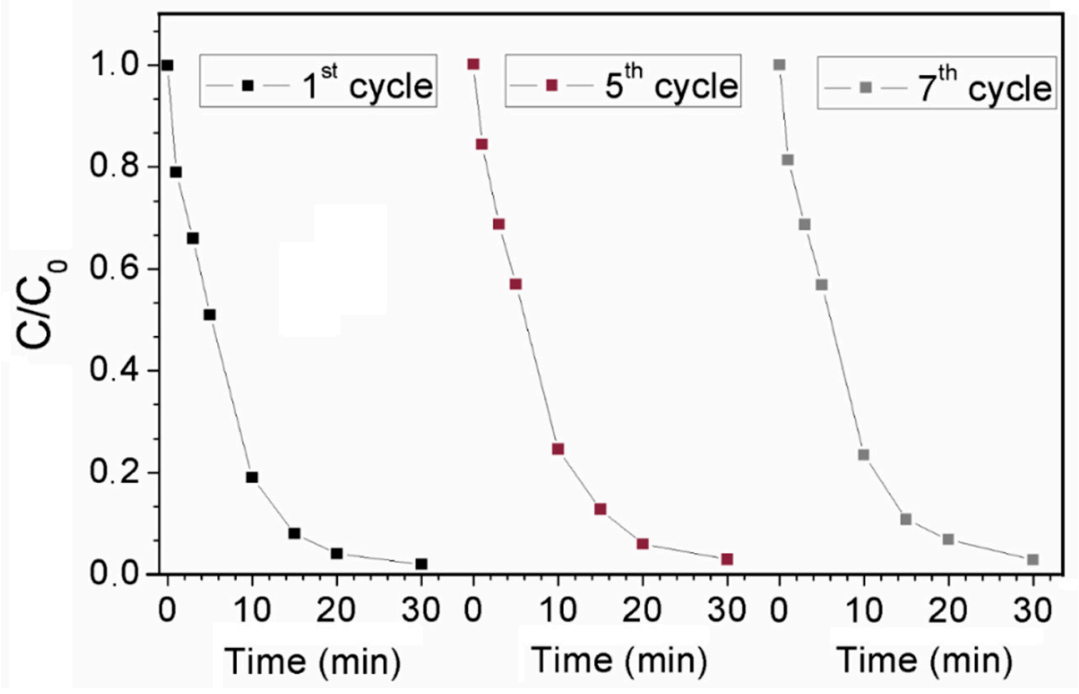

Figure 5. The recycling test for hematite photo-Fenton catalyst obtained by thermal transformation of goethite (sample name FeOOH-800) in the degradation of MB $10 \mathrm{mg} / \mathrm{mL}$ under visible light at neutral $\mathrm{pH}$.

Furthermore, to test the feasibility of the hematite catalyst (FeOOH-800), the photo-Fenton test was driven in the natural sunlight. As can been seen from Figure 6, the MB was completely degraded in $10 \mathrm{~min}$ (rate constant $\mathrm{k}=0.247 \mathrm{~min}^{-1}$ ). The corresponding UV-vis spectral curves of MB solution in natural sunlight is demonstrated in ESI Figure S7. The catalytic activity of the material in sunlight was better than under LED light with an effective power density of $45 \pm 3 \mathrm{~mW} / \mathrm{cm}^{2}$. This is attributed to the higher intensity of sunlight $\left(70.8 \mathrm{~mW} / \mathrm{cm}^{2}\right)$ during the measurement. The experiment clearly indicates that the synthesized material can be effectively used for water treatment driven by natural sunlight. 


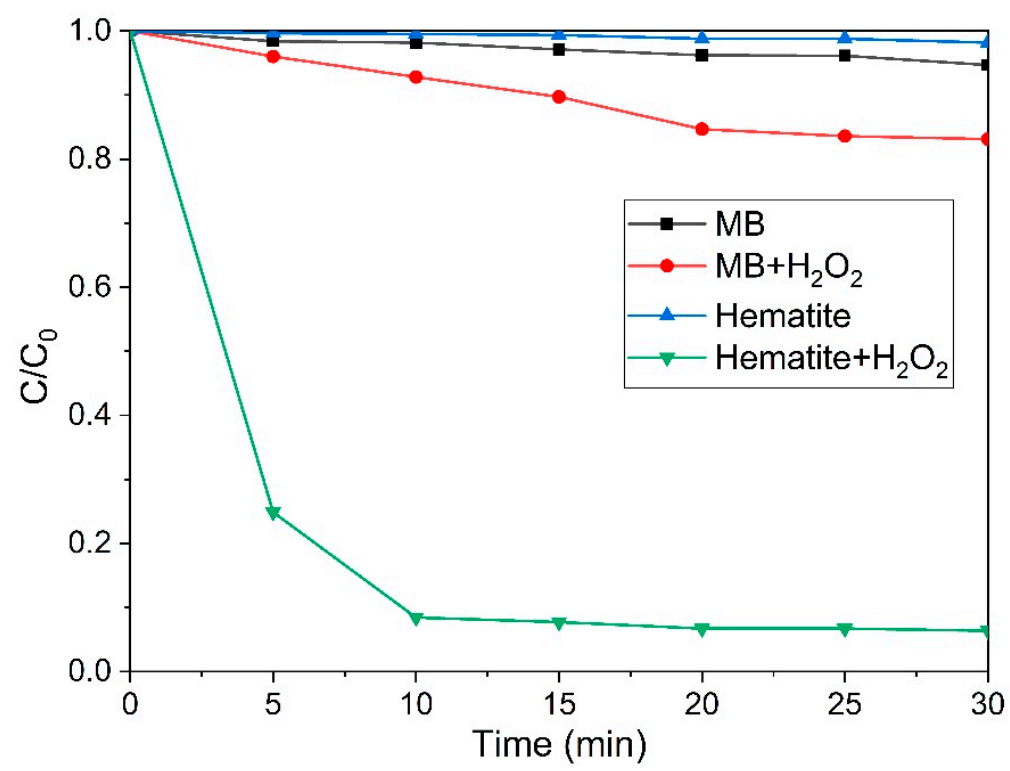

Figure 6. The degradation of $\mathrm{MB}$ in the presence hematite photo-Fenton catalyst (sample name FeOOH-800) under natural sunlight at neutral $\mathrm{pH}$.

\section{Materials and Methods}

\subsection{Sample Synthesis}

The amorphous $\mathrm{FeO}(\mathrm{OH})$ particles were synthesized by hydrolysis of iron (iii) nitrate in $0.1 \mathrm{M}$ solution using $0.5 \mathrm{M}$ hexamethylenetetramine (HMTA) solution. The iron (iii) nitrate and HMTA solutions were mixed at room temperature and dark brown precipitates were collected after stirring for $10 \mathrm{~min}$. The hematite and goethite nanoparticles were synthesized by hydrolysis of iron (iii) nitrate in $0.1 \mathrm{M}$ solution by the addition of $\mathrm{NaOH}$ base solution in a equimolar ratio. The crystalline phases of precipitated iron species were controlled by changing the molarity of the $\mathrm{NaOH}$ solution. Hematite was obtained when $0.25 \mathrm{M} \mathrm{NaOH}$ was used to adjust the solution $\mathrm{pH}$ to 2.9 , while goethite formed when using $0.5 \mathrm{M} \mathrm{NaOH}$ to adjust the solution $\mathrm{pH}$ to 12.8 . After the solutions were mixed at room temperature, they were left for stirring for the next $30 \mathrm{~min}$. Further, the mixtures were kept in a closed half-filled bottle at $60^{\circ} \mathrm{C}$ for $72 \mathrm{~h}$ to observe crystallization of desired phases. After synthesis, all products were washed on a filter and dried. All reagents were chemical grade, supplied by Sigma-Aldrich (Saint Louis, MO, USA) and used as received.

To transform amorphous $\mathrm{FeO}(\mathrm{OH})$ and goethite particles to $\mathrm{Fe}_{2} \mathrm{O}_{3}$, the powders were heated in an ambient air atmosphere at $800{ }^{\circ} \mathrm{C}$ for $20 \mathrm{~min}$.

\subsection{Sample Characterisation}

Crystalline phases of the synthesized sample powders were analyzed by X-ray powder diffraction (XRD), recorded at $2 \theta$ from $15^{\circ}$ to $80^{\circ}$ by using a Rigaku Ultima + diffractometer (Prague, Czech Republic) with $\mathrm{Cu}-\mathrm{K} \alpha$ radiation. The scanning electron microscopy (SEM) studies were performed by using a high-resolution scanning electron microscopy (SEM, Helios Nanolab, FEI, Hillsboro, OR, USA), but transmission electron microscopy (TEM) studies were performed on a Tecnai G2 F20, FEI operated at $200 \mathrm{kV}$. The specific surface area of the nanopowder was analyzed by recording nitrogen adsorption-desorption isotherms using a NOVA 1200e instrument (Quantachrome, Hampshire, UK). The optical properties were studied by measuring diffuse reflectance using a UV-Vis-NIR spectrophotometer (Shimadzu UV3700, Kyoto, Japan). 


\subsection{Photo-Fenton and Photocatalysis Tests}

The photocatalytic and photo-Fenton activity of the synthesized samples was studied by the degradation of $\mathrm{MB}, \mathrm{MO}$ and $\mathrm{RhB}$ in the water at neutral $\mathrm{pH}$ (if not specified). Before tests, sample powders were dispersed by a Hielscher UPS200 (Berlin, Germany) homogenizer in high concentration dye solution $(50 \mathrm{mg} / \mathrm{L})$ to saturate catalyst surface with particular dye and exclude the effects of adsorption in degradation tests. After keeping sample powder in high concentration dye solution for $1 \mathrm{~h}$, catalyst material was centrifuged and re-dispersed in dye solution with a concentration of $10 \mathrm{mg} / \mathrm{L}$. In photo-Fenton tests, the $\mathrm{H}_{2} \mathrm{O}_{2} 161 \mu \mathrm{mol} / \mathrm{mL}$ (or another amount in some particular tests) was added to the solution. The sample powder suspensions were irradiated by a $100 \mathrm{~W}$ light-emitting diode (LED) light source (emission band approximately 415-700 nm, i.e., $2.99 \mathrm{eV}$ to $1.77 \mathrm{eV}$ ) with an effective power density of $45 \pm 3 \mathrm{~mW} / \mathrm{cm}^{2}$. The tests were performed at room temperature, in closed $20 \mathrm{~mL}$ glass vials under constant stirring. The $\mathrm{pH}$ value of the suspensions was controlled by using $\mathrm{HCl}$ and $\mathrm{NaOH}$ with molar concentrations $0.1 \mathrm{M}$. The dye degradation was monitored by taking sample aliquots $1.5 \mathrm{~mL}$ from each suspension after a certain time interval. After centrifuging, the supernatant was analyzed by the UV-NIR spectrophotometer (Thermo Scientific Genesys 10S UV-Vis, Basel, Switzerland). In recycling tests, sample powders were centrifuged and the whole procedure was repeated from the start. The rate constant $(\mathrm{k})$ of dye degradation was observed from a pseudo-first-order reaction kinetic equation, $-\ln \left(C / C_{0}\right)=k t$, where $C_{0}$ and $C$ are the absorption peak intensity of dye before and after some time $(t)$.

To estimate if there is no iron leakage from hematite during the tests and no contribution from the homogeneous Fenton process, the hematite powder was dispersed in water containing $\mathrm{H}_{2} \mathrm{O}_{2}$ $161 \mu \mathrm{mol} / \mathrm{mL}$ and irradiated by the same LED light for $24 \mathrm{~h}$. After that, sample powder was removed by centrifugation, the fresh $\mathrm{H}_{2} \mathrm{O}_{2} 161 \mu \mathrm{mol} / \mathrm{mL}$ and $\mathrm{MB} 10 \mathrm{mg} / \mathrm{L}$ was added to the water and dye degradation was monitored in dark at $\mathrm{pH} 3$.

\section{Conclusions}

The photo-Fenton activity of hematite catalytic materials, obtained by thermal phase transformation from iron-bearing particles, is highly determined by the nanoparticle precursor used. High visible light active hematite photo-Fenton catalyst was obtained by the thermal transformation from goethite $\alpha$-FeOOH nanowires. The high visible light photo-Fenton activity for a particular hematite catalyst is due to the one-dimensional nanoplatelet structure and the presence of nanopores. An obtained photo-Fenton catalyst can be used for the degradation of various dyes in water under sunlight at a neutral $\mathrm{pH}$ and is very stable, with no sign of activity loss in seven cycles.

Supplementary Materials: The following are available online at http://www.mdpi.com/2073-4344/10/7/778/s1, Figure S1: TEM image of goethite nanowires, Figure S2: UV-vis-NIR absorption spectra (Kubleka-Munk function) of various photo-Fenton catalysts (a); optical absorption $(\alpha \mathrm{h} v)^{1 / 2}$ versus photon energy plots for hematite samples (b) and $(\alpha \mathrm{h} v)^{2}$ versus photon energy plots for goethite, Figure S3: UV-vis spectral curves of MB solution in the photo-Fenton degradation process in the presence of FeOOH-800 sample, Figure S4: The MB (10 mg/mL) degradation in presence of $\mathrm{H}_{2} \mathrm{O}_{2}(161 \mu \mathrm{mol} / \mathrm{mL})$ at $\mathrm{pH} 3$ and dark in water in which the hematite sample was stirred and irradiated for $24 \mathrm{~h}(\mathbf{a})$ and freshwater (b). The test was executed to find out if there is no iron leakage from the sample and there is no influence of the homo-Fenton process on degradation. The sample powder was removed before this test, Figure S5: MB $(10 \mathrm{mg} / \mathrm{mL})$ degradation in water in the presence of hematite (sample FeOOH-800) photo-Fenton catalyst under visible light at neutral $\mathrm{pH}$ and different $\mathrm{H}_{2} \mathrm{O}_{2}$ concentration, Figure S6: MB $(10 \mathrm{mg} / \mathrm{mL})$ degradation in water in the presence of hematite (sample FeOOH-800) photo-Fenton catalyst under visible light at different $\mathrm{pH}$, Figure S7: UV-Vis spectra for (a) MB; (b) MB with $\mathrm{H}_{2} \mathrm{O}_{2}$; (c) MB with hematite catalyst; (d) MB with hematite catalyst and $\mathrm{H}_{2} \mathrm{O}_{2}$ under solar irradiation.

Author Contributions: Writing—original draft preparation, A.Š. (Anna Šutka); writing—review and editing, A.Š. (Andris Šutka); material synthesis, A.Š. (Anna Šutka) and S.V.; investigation, A.Š. (Anna Šutka), A.T. and K.Š., A.S., L.M., M.V. and R.E. All authors have read and agreed to the published version of the manuscript.

Funding: This reseach was funded by the European Regional Development Fund within the Activity 1.1.1.2 "Post-doctoral Research Aid" of the Specific Aid Objective 1.1.1 "To increase the research and innovative capacity 
of scientific institutions of Latvia and the ability to attract external financing, investing in human resources and infrastructure" of the Operational Programme "Growth and Employment" (No. 1.1.1.2/VIAA/1/16/157).

Acknowledgments: This work has been supported by the European Regional Development Fund within the Activity 1.1.1.2 "Post-doctoral Research Aid" of the Specific Aid Objective 1.1.1 "To increase the research and innovative capacity of scientific institutions of Latvia and the ability to attract external financing, investing in human resources and infrastructure" of the Operational Programme "Growth and Employment" (No. 1.1.1.2/VIAA/1/16/157).

Conflicts of Interest: The authors declare no conflict of interest. The funders had no role in the design of the study; in the collection, analyses, or interpretation of data; in the writing of the manuscript, or in the decision to publish the results.

\section{References}

1. Nidheesh, P. Heterogeneous Fenton catalysts for the abatement of organic pollutants from aqueous solution: A review. RSC Adv. 2015, 5, 40552-40577. [CrossRef]

2. Xiao, Y.; Deng, Y.; Huan, W.; Li, J.; Zhang, J.; Xing, M. Hollow-structured $\mathrm{Fe}_{2} \mathrm{O}_{3} / \mathrm{Au} / \mathrm{SiO}$ nanorods with enhanced and recyclable photo-Fenton oxidation for the remediation of organic pollutants. Mater. Today Chem. 2019, 11, 86-93. [CrossRef]

3. Tian, S.; Zhang, J.; Chen, J.; Kong, L.; Lu, J.; Ding, F.; Xiong, Y. $\mathrm{Fe}_{2}\left(\mathrm{MoO}_{4}\right)_{3}$ as an Effective Photo-Fenton-like Catalyst for the Degradation of Anionic and Cationic Dyes in a Wide pH Range. Ind. Eng. Chem. Res. 2013, 52, 13333-13341. [CrossRef]

4. Wang, X.; Wang, J.; Cui, Z.; Wang, S.; Cao, M. Facet effect of a-Fe $\mathrm{F}_{2} \mathrm{O}_{3}$ crystals on photocatalytic performance in the photo-Fenton reaction. RSC Adv. 2014, 4, 34387-34394. [CrossRef]

5. Zhou, X.; Lan, J.; Liu, G.; Deng, K.; Yang, Y.; Nie, G.; Yu, J.; Zhi, L. Facet-mediated photodegradation of organic dye over hematite architectures by visible light. Angew. Chem. Int. Ed. 2012, 51, 178-182. [CrossRef] [PubMed]

6. Changotra, R.; Varshney, L.; Guin, J.P.; Dhir, A. Performance of hematite particles as an Iron source for the degradation of ornidazole in photo-fenton process. J. Sol-Gel Sci. Technol. 2018, 85, 203-212. [CrossRef]

7. Zhang, Y.; Zhang, N.; Wang, T.; Huang, H.; Chen, Y.; Li, Z.; Zou, Z. Heterogeneous degradation of organic contaminants in the photo-Fenton reaction employing pure cubic $\beta-\mathrm{Fe}_{2} \mathrm{O}_{3}$. Appl. Catal. B Environ. 2019, 245, 410-419. [CrossRef]

8. Wang, F.; Yu, X.; Ge, M.; Wu, S.; Guan, J.; Tang, J.; Wu, X.; Ritchie, R.O. Facile self-assembly synthesis of $\gamma$ Fe2O3/graphene oxide for enhanced photo-Fenton reaction. Environ. Pollut. 2019, 248, 229-237. [CrossRef]

9. Ruales-Lonfat, C.; Barona, J.; Sienkiewicz, A.; Bensimon, M.; Colmenares, J.J.V.; Benítez, N.; Pulgarin, C. Iron oxides semiconductors are efficients for solar water disinfection: A comparison with photo-Fenton processes at neutral Ph. Appl. Catal. B Environ. 2015, 166-167, 497-508. [CrossRef]

10. Xu, J.; Li, Y.; Yuan, B.; Shen, C.; Fu, M.; Cui, H.; Sun, W. Large scale preparation of Cu-doped $\alpha$-FeOOH nanoflowers and their photo-Fenton-like catalytic degradation of diclofenac sodium. Chem. Eng. J. 2016, 291, 174-183. [CrossRef]

11. Xu, Z.; Yu, Y.; Fang, D.; Xu, J.; Liang, J.; Zhou, L. Microwave-ultrasound assisted synthesis of $\beta$-FeOOH and its catalytic property in a photo-Fenton-like process. Ultrason. Sonochem. 2015, 27, 287-295. [CrossRef] [PubMed]

12. Dükkanc1, M. Sono-photo-Fenton oxidation of bisphenol-A over a $\mathrm{LaFeO}_{3}$ perovskite catalyst. Ultrason. Sonochem. 2018, 40, 110-116.

13. Soltani, T.; Lee, B.-K. Enhanced formation of sulfate radicals by metal-doped $\mathrm{BiFeO}_{3}$ under visible light for improving photo-Fenton catalytic degradation of 2-chlorophenol. Chem. Eng. J. 2017, 313, 1258-1268. [CrossRef]

14. Sharma, R.; Bansal, S.; Singhal, S. Tailoring the photo-Fenton activity of spinel ferrites $\left(\mathrm{MFe}_{2} \mathrm{O}_{4}\right)$ by incorporating different cations ( $\mathrm{M}=\mathrm{Cu}, \mathrm{Zn}, \mathrm{Ni}$ and $\mathrm{Co})$ in the structure. RSC Adv. 2015, 5, 6006-6018. [CrossRef]

15. Anchieta, C.G.; Severo, E.C.; Rigo, C.; Mazutti, M.A.; Kuhn, R.C.; Müller, E.I.; Flores, E.M.; Moreira, R.D.F.P.M.; Foletto, E.L. Rapid and facile preparation of zinc ferrite $\left(\mathrm{ZnFe}_{2} \mathrm{O}_{4}\right)$ oxide by microwave-solvothermal technique and its catalytic activity in heterogeneous photo-Fenton reaction. Mater. Chem. Phys. 2015, 160, 141-147. [CrossRef]

16. Wen, Y.; Zhao, Y.; Guo, M.; Xu, Y. Synergetic effect of $\mathrm{Fe}_{2} \mathrm{O}_{3}$ and $\mathrm{BiVO}_{4}$ as photocatalyst nanocomposites for improved photo-Fenton catalytic activity. J. Mater. Sci. 2019, 54, 8236-8246. [CrossRef] 
17. Yao, Y.; Cai, Y.; Lu, F.; Qin, J.; Wei, F.; Xu, C.; Wang, S. Magnetic $\mathrm{ZnFe}_{2} \mathrm{O}_{4}-\mathrm{C}_{3} \mathrm{~N}_{4}$ hybrid for photocatalytic degradation of aqueous organic pollutants by visible light. Ind. Eng. Chem. Res. 2014, 53, 17294-17302. [CrossRef]

18. Wu, Z.; Zhu, W.; Zhang, M.; Lin, Y.; Xu, N.; Chen, F.; Wang, D.; Chen, Z. Adsorption and synergetic Fenton-like degradation of methylene blue by a novel mesoporous $\alpha-\mathrm{Fe}_{2} \mathrm{O}_{3} / \mathrm{SiO}_{2}$ at neutral $\mathrm{pH}$. Ind. Eng. Chem. Res. 2018, 57, 5539-5549. [CrossRef]

19. Zandi, O.; Hamann, T.W. Determination of photoelectrochemical water oxidation intermediates on haematite electrode surfaces using operando infrared spectroscopy. Nat. Chem. 2016, 8, 778-783. [CrossRef]

20. Zhao, Y.; Jiangyong, H.; Chen, H. Elimination of estrogen and its estrogenicity by heterogeneous photo-Fenton catalyst $\beta-\mathrm{FeOOH} /$ resin. J. Photoch. Photobio. A Chem. 2012, 212, 94-100. [CrossRef]

21. Liu, X.; Liu, J.; Chang, Z.; Sun, X.; Li, Y. Crystal plane effect of $\mathrm{Fe}_{2} \mathrm{O}_{3}$ with various morphologies on $\mathrm{CO}$ catalytic oxidation. Catal. Commun. 2011, 12, 530-534. [CrossRef]

22. Mao, Y.; Wong, S.S. Size-and shape-dependent transformation of nanosized titanate into analogous anatase titania nanostructures. J. Am. Chem. Soc. 2006, 128, 8217-8226. [CrossRef] [PubMed]

23. Zboril, R.; Mashlan, M.; Petridis, D. Iron(III) oxides from thermal processes synthesis, structural and magnetic properties, Mössbaueer Spectroscopy Characterization, and Applications. Chem. Mater. 2002, 14, 969-982. [CrossRef]

24. Zhou, H.; Yi, R.; Li, J.; Su, Y.; Liu, X. Microwave-assisted synthesis and characterization of hexagonal $\mathrm{Fe}_{3} \mathrm{O}_{4}$ nanoplates. Solid State Sci. 2010, 12, 99-104. [CrossRef]

25. Šutka, A.; Järvekülg, M.; Gross, K.A.; Kook, M.; Käämbre, T.; Visnapuu, M.; Trefalt, G.; Šutka, A. Visible light to switch-on desorption from goethite. Nanoscale 2019, 11, 3794-3798. [CrossRef]

26. Wang, B.; Bin Wu, H.; Yu, L.; Xu, R.; Lim, T.-T.; Lou, X.W. Template-free formation of uniform urchin-like $\alpha$-FeOOH hollow spheres with superior capability for water treatment. Adv. Mater. 2012, 24, 1111-1116. [CrossRef] [PubMed]

27. Jia, C.J.; Sun, L.D.; Yan, Z.G.; You, L.P.; Luo, F.; Han, X.D.; Yan, C.H.; Han, X.-D.; Pang, Y.-C.; Zhang, Z. Single-crystalline iron oxide nanotubes. Angew. Chem. Int. Ed. 2005, 44, 4328-4333. [CrossRef]

28. Šutka, A.; Vanags, M.; Joost, U.; Smits, K.; Ruža, J.; Locs, J.; Kleperis, J.; Juhna, T. Aqueous synthesis of Z-scheme photocatalyst powders and thin-film photoanodes from earth abundant elements. J. Environ. Chem. Eng. 2018, 6, 2606-2615. [CrossRef]

29. Cornell, R.M.; Giovanoli, R.; Schneider, W. Review of the hydrolysis of iron(III) and the crystallization of Amorphous Iron(III) Hydroxide Hydrate. J. Chem. Tech. Biotechnol. 1989, 46, 115-134. [CrossRef]

30. Johnston, J.H.; Lewis, D.G. A detailed study of the transformation of ferrihydrite to haernatite in an aqueous medium at $92^{\circ} \mathrm{C}$. Geochim. Cosmochim. Acta 1983, 47, 1823-1831. [CrossRef]

31. Murphy, A.B. Band-gap determination from diffuse reflectance measurements of semiconductor films, and application to photoelectrochemical water-splitting. Sol. Energy Mat. Sol. Cells 2007, 91, 1326-1337. [CrossRef]

32. Sivula, K.; Le Formal, F.; Grätzel, M. Solar water splitting: Progress using hematite $\left(\alpha-\mathrm{Fe}_{2} \mathrm{O}_{3}\right)$ photoelectrodes. Chem. Sus. Chem. 2011, 4, 432-449. [CrossRef] [PubMed]

33. Loeb, S.K.; Alvarez, P.J.J.; Brame, J.A.; Cates, E.L.; Choi, W.; Crittenden, J.; Dionysiou, D.D.; Li, Q.; Puma, G.L.; Quan, X.; et al. The technology horizon for photocatalytic water treatment: Sunrise or sunset? Environ. Sci. Technol. 2019, 53, 2937-2947. [CrossRef]

34. Leelavathi, A.; Madras, G.; Ravishankar, N. Origin of enhanced photocatalytic activity and photoconduction in high aspect ratio ZnO nanorods. Phys. Chem. Chem. Phys. 2013, 15, 10795-10802. [CrossRef] [PubMed]

35. Cornell, R.M.; Schwertmann, U. The Iron Oxides: Structure, Properties, Reactions, Occurrences and Uses; Wiley-VCH Verlag: Weinhein, Germany, 2003.

(C) 2020 by the authors. Licensee MDPI, Basel, Switzerland. This article is an open access article distributed under the terms and conditions of the Creative Commons Attribution (CC BY) license (http://creativecommons.org/licenses/by/4.0/). 